\title{
SUSTAINABILITY, EDUCATION AND INTERIOR DESIGN- INTERRELATED ASPECTS: THE CASE OF CYPRUS
}

\author{
P. Lapithis, K. Ioannou Kazamia \\ University of Nicosia (CYPRUS)
}

\begin{abstract}
Interior Designers have a unique role and responsibility as the intermediary between industry and clients, and while much guidance and regulation is being introduced across Europe, this is not the case for the field of interior design and its professionals in Cyprus, as the interior design profession is not yet legally regulated.
\end{abstract}

A crucial argument is whether environmentally responsible design should be regarded as a specialisation within design education. The construction of schools which are set to be models of environmental responsibility is becoming very important. A general understanding of sustainability means to restore, preserve and enhance nature and culture for the benefit of life for present and future generations. Unfortunately, no data is available regarding the scale of interior design practice or the proportion of interior design-associated expenditure controlled by professionals, and indeed this research is the first that deals with the interior design profession in Cyprus.

This paper presents the situation and education for sustainable development in Cyprus and at the same time discusses organising principles for teaching sustainability within the interior design profession and how all these different efforts come together with specific findings and proposals. Examples of courses, workshops, seminars, presentations and skills that the students, the professionals and the clients should attain within the interior design education and profession are discussed.

Further research has been done for Cyprus regarding Sustainability and Interior Design Practice, Waste Management, Education for Sustainable Development, the School Network and the Community, Implementing Sustainability within the Interior Design Curriculum. The activities undertaken to promote sustainability by some organizations are worthy examples and are considered for the promotion of sustainable interior design practices. Education for Sustainable Design carries with it the inherent idea of implementing programs that are locally relevant and culturally appropriate. All sustainable development programs including ESD take into consideration the local environmental, economic, and societal conditions.

Keywords: Sustainability, Education, Interior Design, Cyprus

\section{INTRODUCTION}

According to the European Council of Interior Architects (ECIA) [1] the professional Interior Architect/Interior Designer is a person, qualified by education, experience and recognized skills, who Identifies, researches and creatively solves problems pertaining to the function and quality of the interior environment; and performs services relative to interior spaces including programming, design analysis, space planning, aesthetics and inspection of work on site, using specialized knowledge of interior construction, building systems and components, building regulations, equipment, materials and furnishings; and prepares drawings and documents relative to the design of interior space, in order to enhance the quality of life and protect the health, safety and welfare of the public [1].

The impact of architecture and interior design practice on humans and their environment is apparent. There is an emergent requirement for design stakeholders to adapt the way they prepare, practice, and repeat this practice to a new reality [2]. Sustainability can be described as a state or process that can be maintained indefinitely. The principles of sustainability integrate three closely interlinked aspects, namely the environment, economy, and social [3]. Moreover, the sustainable design includes using design methods, products, and procedures that minimize the ecological influence of design and construction upon the earth [4].

In Cyprus, a number of cases can be regarded as good practice concerning the issue of sustainability, nevertheless a lot of steps need to be considered and taken. The paper, looks upon those and present 
how this good practices can be applied into tertiary education curriculum and to point the interrelation of sustainability and interior design/ architecture education.

Based on that, the paper suggests that professionals' formal education have a unique role and responsibility towards the industry and while a lot of guidance and legislation is being introduced, this is not yet the case for the tertiary education in Cyprus. The results of the implementation of relevant courses at the University of Nicosia shows that the implementation is pertinent to professors' initiatives and research interest.

\section{EDUCATION FOR SUSTAINABLE DEVELOPMENT AND CYPRUS}

\subsection{Education for Sustainable Development}

Education for Sustainable Development (ESD) carries with the inherent idea of implementing programs that are locally relevant and culturally appropriate. All sustainable development programs including ESD must take into consideration the local environmental, economic, and societal conditions. There are four major thrusts to begin the work of ESD [5]:

1. Improving Basic Education: If communities and nations hope to identify sustainability goals and work toward them, they must focus on skills, values, and perspectives that encourage and support public participation and community decision making.

2. Reorienting Existing Education: An appropriately reoriented basic education includes more principles, skills, perspectives, and values related to sustainability than are currently included in most education systems.

3. Public Understanding and Awareness: Sustainability requires a population that is aware of the goals of a sustainable society and has the knowledge and skills to contribute to those goals.

4. Training: Training is distinct from education in that training is often specific to a particular job or class of jobs.

\subsection{The Cyprus Pedagogical Institute}

The Cyprus Pedagogical Institute (CPI) [6] is the coordinating body for the systematic promotion and implementation of actions related to education for sustainable development (ESD) in the Cyprus education system. The draft of the National Strategy for ESD encompasses eight fundamental action areas among those the following are included [7]:

1. Forming an institutional and operational framework for integrating ESD in Cypriot formal and non-formal educational systems.

2. Promoting ESD-related research and evaluation.

3. Developing educational tools in cooperation with other countries, NGOs, and other interested sectors at national level.

4. Creating a network of Environmental Education Centres, the Green Schools. The main aim of these Centres will be to connect formal and non-formal education, according to the needs of Society.

An innovative project for effectively promote ESD in Cyprus is the project "Students in Research and Evaluation". Through this project schools have the opportunity to develop various Environmental Education Programmes based on ESD. "Sustainable Cities", "Car-free Cities", "Eco-tourism", "Renewable Energy Resources" are some of the projects that have already been developed. The projects are pursued through students' investigation and interaction with their local community, governmental organizations and NGOs so as to propose solutions for the improvement of their community's living conditions.

In order to achieve the above, a number of actions were promoted by the CPI. Therefore a sequence of actions like for example the systematic promotion of sustainable development in the Cyprus educational system, sustained during previous years has culminated in today's required results. The different actions and projects supported by the $\mathrm{CPI}$, and the systematic promotion of sustainability issues among different stakeholders is very good practice for the wide spread of the sustainability issue. Connecting formal with non-formal education is a good approach to be considered. 


\subsection{Waste Management in Cyprus}

According to European legislation 'Waste' is defined "as any substance or object which the holder discards or intends to or is required to discard. There are ten categorization of waste according European Environment Agency [8]:

- Municipal waste

- Industrial waste

- Hazardous waste

- Construction and demolition waste

- Mining waste

- Waste from electrical and electronic equipment (WEEE)

- Biodegradable municipal waste

- Packaging waste

- Agricultural waste

- Vehicles and tyres

Both waste disposal and waste treatment can have negative effects on both the quality of the environment and human health. Waste adversely affect the area in which are deposited or process contaminating the air, water and soil until their complete decomposition. The duration for the complete decomposition of a material vary depending material and its composition. Although Cyprus is an extremely small part of the European Union measurements recorded on waste exceeds greatly the EU average. From 2001 until 2010 there is an increase in the number of waste is at least $25 \%$, with a dramatic increase over the period of 2009 [9].

The entry of Cyprus to the EU inevitably affects the field of environmental protection and arrested in the creation and development of relevant legislation. The Republic of Cyprus to align its legislation of the European Acquis has proceeded to establish relevant laws with the best possible management of waste and consequently the protection of the environment [10]:

- The Solid and Hazardous Waste Regulations (2003)

- The Waste Law (2011)

- Packaging and Packaging Waste Law (2002) [9].

In Cyprus, the solid waste management sector falls its competence of the Minister of Interior. The minister follows a strategic planning in terms of waste management based on the above legislations. Until recently more than $80 \%$ of waste ended to uncontrolled waste disposal sites, since was the main way for the treatment and management of waste on the island, due to the lack of adequate and appropriate facilities.

The recycling sector in Cyprus is based on non-governmental organizations. In 2006 with the foundation of Green Dot Cyprus began efforts to inform and sensitize the public and promote recycling. During the last ten years in the field of recycling observed slow but steady increase. The recycling sector in Cyprus is only addressed to materials such as glass, paper, plastic and aluminium. The competent authority has proceeded to a separate collection of materials into separate containers in order to ensure the best quality of the new product.

Together with the Green Dot Cyprus Ltd have also licensed additional 3 companies, WEEE Electrocyclosis Ltd for electrical and electronic waste, the AFIS Ltd for batteries and latterly the RTM for waste tires, that collect and export waste directly in units abroad because of the lack of proper installation in Cyprus.

\subsection{The Electricity Authority of Cyprus}

Cyprus relies heavily on fossil fuel imports, as it has no energy resources other than mainly solar and wind energy [11]. A legislative framework had to be created to provide the necessary background for the implementation of the action plan and to legally support schemes for the promotion of RES. The outcome was the Energy Performance of Buildings Directive. To create the framework, which legitimised the actions and measures taken to achieve the organisation's strategic objectives, the EAC, as a semi-governmental organisation, drafted a 2003 law for the promotion of the use of RES and energy conservation investments. Furthermore, the EAC's overarching strategic objective is to be a leader in sustainability [12]. The measures the government and EAC employed included promoting greater stakeholder involvement through rewards such as sponsorship and funding. 


\subsection{The Cyprus Marine Environment Protection Association}

The principal aim of CYMEPA is to encourage and actively assist efforts to prevent all forms of pollution of the sea. The shipping community of Cyprus, comprising ship-owners, operators, ship managers and agents, masters, deck and engineer officers and seafarers, and other maritime sector industries and professions, representing a fleet of some 22 million gross tons of commercial shipping, and many other related industries and activities have voluntarily committed to eliminating shipgenerated marine pollution specifically and marine pollution generally.

CYMEPA initiates environmental projects and operates extensive public awareness campaigns, prioritising the environmental education of schoolchildren. Furthermore, CYMEPA supports and assists the government of Cyprus in ratifying and implementing international conventions addressing the protection of the marine environment. CYMEPA's declaration states the following: "Information must be disseminated and environmental consciousness originated through formal and informal education; training and all kinds of networks so that needed environmental actions are as widely understood as possible" [13].

\subsection{Environmental Studies Centre}

The Environmental Studies Centre (ESC) [14] is a notable centre for practical environmental education or field studies on the island of Cyprus. Groups of students of all ages come to study ecology, geography, tourism, and other environmental subjects appropriate to the area, following programmes from one to 10 days in length. Course programmes are designed to meet the needs of individual groups, based always on the principle that there is no better classroom to learn about nature and the landscape than the countryside itself. The ESC represents the main educational activity of the Terra Cypria Foundation, a registered charity concerned with raising environmental awareness throughout Cypriot society.

\subsection{The Public School Network and the Community in Cyprus}

Every contemporary school according to regulations of the Ministry of Education of Cyprus-"must follow the contemporary needs of education. The composition and morphology of the building must respond to the teaching methodologies in order for the student to have an energetic and interactive way of learning, contrary to the old methodology of memorization. Especially care must be given on the subjects of lightning, acoustics and ventilation. The forms of organization of space must help the promotion of basic educational objectives like the cultivation of fantasy, critical thinking, collectively and children initiative. The schools as a living organism must be open to the community and public facilities of the building have to be open throughout the year. The outdoor space of the school must contribute to outdoor learning activities and the landscape has to be enriched with local flora of Cyprus." [15]

The construction of schools which are set to be models of environmental responsibility is becoming very important. A general understanding of sustainability means to restore, preserve and enhance nature and culture for the benefit of life for present and future generations. Sustainable design for buildings means the maximization of positive effects of the building on a series of aspects concerning the human systems and nature, and minimizing its negative impacts, over the whole of its life. The design process should bring together the following elements in an integrated package [16]:

- Accessibility

- Energy

- Water

- Nature

- Materiality

- Built Heritage

- Community

- Health

For schools to achieve the status of becoming centres of the community there are two ways. The first way is to effectively integrate with the community, or the other way is to extend the learning environment to use the community's full range of resources. An integrated school is the school being able to serve residents in numerous ways. For example, later or longer hours may permit senior citizens to use the athletic facilities during non-school hours, or immigrants to take evening Greek or English classes after work [16]. 
Concerning sustainability the creation and extension of compost and recycling centres in schools, or small power stations based on renewable energy sources (especially photovoltaic panels), can create a network of energy or a network of waste management, using a very small amount of the existing built infrastructure. The school space takes other functions further than its educational purpose. It becomes a space of active participation on the serious subjects of management of these technological systems and a space not only of concern and theoretical investigation but of practical application and implementation of knowledge. The adaption of these practices in every school automatically creates through the management of these systems - a network of schools, a network of small power stations, a network of small compost and recycling centres, that their functioning requires to be connected.

\section{IMPLEMENTING SUSTAINABILITY}

\subsection{Interior Design in Practice}

In practice, interior design typically takes place under two conditions. First, interior designers usually must consider the existing circumstances for a particular space, and they are often limited by the more or less fixed elements of the construction [17]. This applies when designers work with existing spaces and when architectural planning has been completed before interior design begins. Therefore, designers seldom contribute to spatial design. The second condition, which is ideal, is for the process of interior design planning to begin along with the architectural planning.

The issues of objects or materials and furniture fixture and equipment (FF\&E) selection are of great importance in both of the above two conditions and interior designers should endeavour to practice sustainable design whenever feasible [18]. The American Society of Interior Designers (ASID) [19] recognized that sustainability should be an essential part of the interior designer's professional responsibilities. Moreover, ASID acknowledged that sustainable interior design embraces, among other things, resource and energy efficiency, and noted that interior designers should use renewable natural resources and work to protect the environment, including vegetation, wildlife habitats, open spaces, and wilderness. In addition, the organization addressed waste reduction, advising interior designers to 'minimize waste through the reduction, reuse, or recycling of products, and it encouraged the development and use of reclaimed, salvaged, and recycled products' [20].

These two issues -objects or materials and furniture fixture and equipment (FF\&E) - were explored and classified to show the degree of positive outcomes that can be derived from their application [2]. Both were classified into three different approaches which can support design solutions at various phases during the design process, prolong the longevity of the interior space, and save resources. Those approaches were introduced through a proposed model to promote sustainable practices among designers and clients and test which sustainable practices were the more widespread.

Concerning materials that are always in the scope of interior design projects, the following approaches were suggested through workshops:

- Immediate Term Approach/Use of New Materials

- Medium Term Approach/Use of Recycled Materials

- Long Term Approach/Use of Reclaimed Materials

Concerning design, innovative suggestions are reflected in the three different space design approaches. The three different approaches can support design solutions at various phases during the design process and all three of them can prolong the longevity of the interior space. Those are:

- Immediate Term Approach/Use of Multipurpose Furnishings

- Medium Term Approach/Flexible Space Design

- Long Term Approach/Design for Deconstruction

To promote the uptake of sustainability practices/approaches in the discipline of interior design among interior designers and their clients on the island of Cyprus an action research methodology was employed and affective learning domain as presented by Krathwohl et al. [21], levels and objectives were integrated. 


\subsection{Interior Design Professionals and the Action Research}

Action research is a participatory research method which is usually performed in groups of people who are active in an area and allow participants to explore solutions to real problems which concerned them [22]. Furthermore, as the name suggests, action research is a methodology which has the dual aims of action and research, action to bring about change in some community or organization or programme, and research to increase understanding on the part of the researcher or the client, or both (and often some wider community). The method that this research undertook in order to accommodate the necessary series of interventions can be seen below in Figure 1. It consists of three major action research circles that take place in three subsequent phases. Each phase includes an action research circle and according to the proposed model has as follow [2]:

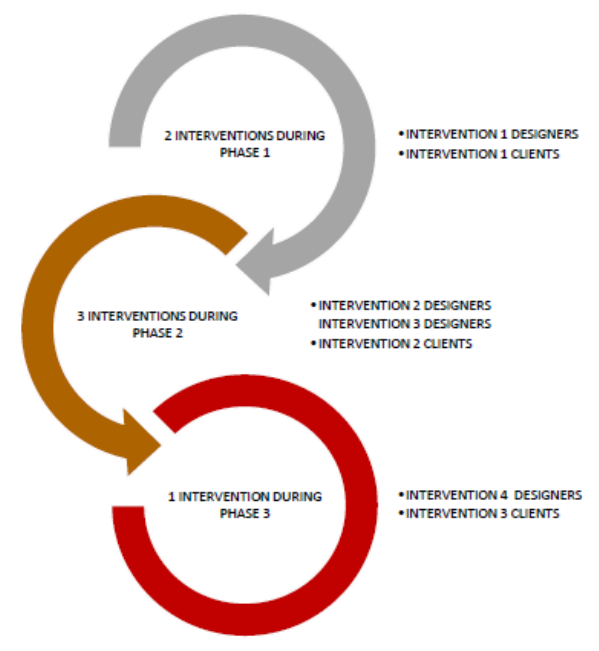

Figure 1. Interventions for each Phase of the Action Research.

1. Cycle one and Phase I diagnosis is the need to unfreeze; Planning action, is the designing of the specific interventions targeting receiving and responding among stakeholders; Taking action, is the attending and reacting to sustainable interior design practices through traditional and experiential learning; and evaluating action, will indicate the degree of creating a felt need for change among the stakeholders;

2. Cycle 2 and Phase II diagnosis is the need to change; Planning action, is the designing of the specific interventions targeting the attachment of new values; Taking action, is the reporting of sustainable interior design practices as of dominant value through collaborative and problem based learning; and evaluating action will indicate the degree of valuing.

3. Cycle three and Phase III diagnosis is the need to refreeze; Planning action is the designing of intervention that will assist stakeholders to organize and characterize themselves according to new values; Taking action is the adaptation of new believe system and philosophy through collaborative learning and evaluating action, is the degree of the reinforcing of the outcomes.

The action research encouraged sustainable practices among groups of participants in a series of interventions in the sense that has been conceptualized. The entire process is premised on the literature review along with the application of the model that considers the understanding of knowledge creation, the change process, the acquisition of new values, and the involvement of stakeholders in promulgating sustainable interior design approaches [2]. In the researcher's viewpoint, this implies the consideration of three factors: first, what is meant by the notion of sustainability in interior design practice and what this implies in terms of thematic knowledge practice; second, the methodological approach that involved an action research in this case and third, the theoretical/learning approach.

The learning approach was guided by Blooms taxonomy [23], who led a group of educational psychologists, developed a classification of levels of intellectual behaviour significant in learning. This became a taxonomy that includes three overlapping domains: 'the cognitive, psychomotor, and affective'. A specific learning approach it was necessary to define how they felt need for change would be transmitted and how stakeholders would adopt new behaviours. The consideration of the affective domain in learning for the stakeholders in this research was important, as we wanted them to alter 
their attitudes towards design practice. As explained by Krathwohl et al. [21], affective learning includes the way we deal with things emotionally, such as feelings, values, appreciation, enthusiasm, motivations, and attitudes.

According to the reported results, all the practices that had been promoted were used, indicating that the participants had reconciled internal conflicts, developed a new value system, and adopted a new belief system/philosophy. The designers admitted that they now, after seeing examples and after the collaboration with their clients, have a better understanding of how they can perform and act using the information given during workshops. Some of the clients acknowledged that the issue of sustainability is now clearly related with interior design, and some other designers comment that the process of preparing and presenting design work was the most enlightening experience. More specifically, the most preferable sustainable practices among designers and their clients are the use of multipurpose furniture and the new materials while flexible space design and recycled materials are the second preferable and deconstructive space designs, with reclaimed materials, the least preferable.

In terms of the application of sustainable practices in interior design, a survey sponsored by the International Interior Design Association [2] revealed that $83 \%$ of professional designers understand that they have an ethical and moral responsibility to offer sustainable design options to their clients, yet the designers provide sustainable solutions in no more than $37 \%$ of projects, despite perceiving the value of sustainable design in its beneficial impact on the environment. While designers consider it their social responsibility to protect the environment and conserve resources, they consider the greater sense of responsibility to lie in the completion of their projects on time and within budget.

\subsection{Sustainable Interior Design within the Educational Curriculum}

A crucial argument is whether environmentally responsible interior designer should be regarded as a specialisation within interior design education or whether the entire spectrum of interior design should be taught as a science and as an art that is equally accountable to man and to the environment. This begs the question, shouldn't interior design always be ecologically responsible?

The Interior Design Programme of University of Nicosia introduced specific courses where sustainable design issues are applied, such as the Interior design studios, Furniture Design, Sustainability in Interior Design, Thesis, Final Year Project, and Sustainable Practices in Interior Design. The primary aim has been to introduce the knowledge and culture of sustainability to young minds and to impart them with such skills that would enable them to bring forth a paradigm shift in professional arena.

Developing an understanding of design, maintenance and operation of the built environment while minimizing energy needs was a strong component of the studio's objectives. These issues were presented to students through a series of in-studio lectures by faculty members, expert guests and fellow students. Presentations were based on theory, case studies, technological advances and social issues. The basic framework of sustainable interior design, such as theory, ecology and technology was also offered to the students through the supplementary courses they take as part of their curriculum.

The content of the Sustainable Practices in Interior Design course includes an introduction to the module during the first session along with a small placement questionnaire and a day brief. Then, during the semester students and instructors work on the following topics in a studio class with lectures, projection of visual material, guest lecturers, assignments (projects), individual instruction, students work presentation and group discussions:

- Sustainable Design: What is it?, why should I do it?-Terminology, Examples

- Environmental Issues -Their relation with the build environment.

- Conscious Design: Resource conservation-Waste management.

- Conscious Design: Resource conservation-Energy efficiency. Alternative, clean sources of energy.

- Conscious Design: Resource conservation-Water management.

- Materials -Linear and cyclical models.

- The importance of indoor environmental quality

As expected outcomes after completion of the course students are likely to be able to: 
- Utilize proper research for the subject matter.

- Compute environmental and sustainable issues related to their profession.

- Demonstrate and determine their ability on the fact that the design of an interior space has to respect the environment and take into consideration natural resources.

- Question traditional approaches to interior design methodology and practice.

- Formulate and compose the most environmentally friendly solutions for projects regarding materials, products and methods specifications for interior installation/construction, lighting, furnishings and equipment selection.

Interior designers' formal education have a unique role and responsibility towards the industry. The context and the topics of the described course is an example of a good practice. It should be noted though that the expected outcomes are based on the cognitive learning levels and objectives (Bloom, Englehart, Furst, Hill, \& Krathwohl) [23] while as is pointed out by Krathwohl et al. [21], affective learning is the learning domain with objectives that give emphasis to feeling tone, an emotion, or a degree of acceptance or rejection and includes the way we deal with things emotionally, such as feelings, values, appreciation, enthusiasm, motivations, and attitudes.

\section{DISCUSSION}

The results from the above presented action research phases suggest that awareness and understanding of the delivery of sustainability within the built environment can increase when it is promoted within an organised and well-structured method. In conclusion, the overall findings of that research suggest that the guidelines recommended by IFI and other professional bodies are welcomed by the stakeholders; however, these guidelines need to be translated into specific practices in order to turn into tangible results. The classification of sustainable practices for interior designers and their clients facilitated a tangible application of the promoted approaches. Additionally, the classification enabled the understanding of the significance of interior design in delivering sustainability within the built environment.

Similarly the activities undertaken to promote sustainability by some organizations are worthy examples and are considered for the promotion of sustainable interior design practices. For instance, following the example of the Electricity Authority of Cyprus, implementing sustainability policies was identified as a valuable long-term plan for interior designers' associations. Similarly, the urgent need for legal regulation of the profession on the island was highlighted. Furthermore, the voluntary commitment of the members of CYMEPA could be used as a guide for the interior design industry. The example of the Cyprus Pedagogical Institute's systematic promotion of ESD among various groups could be emulated in developing a strategy for the systematic promotion of sustainable design issues. Nevertheless, because the Cyprus Pedagogical Institute, has not approached designers to involve them in any activities, designers' associations should take the initiative to involve their members in activities that promote sustainability learning.

The way forward could involve an application of the model presented and suggest how a direction could be established that could assist in the development of an education strategy pertaining to interior architects/designers. This can be applied locally as well as across Europe through the European Charter of Interior Architecture Education. In addition, this development could pave the way for the creation of a further connection between the design associations in Europe and result in the promotion of sustainable practices among a vast number of stakeholders. It is not sufficient for the associations to merely send in information to members; it is imperative to provide a relevant learning environment. Likely, it not sufficient that the implementation of relevant courses, is pertinent to professors' initiatives and research interest. The implementation of courses and relevant policies should be holistic and imperative.

\section{CONCLUSION}

It has been acknowledged that interior design practitioners play a role in sustainability, as the decisions they make in practice affect this issue. Designers' work deals with layers that have fast rate of change in the lifespan of a building and parallel to that, through their work, they have the opportunity to deliver 
to their clients, opinions, norms, and attitudes. In this way, they can influence clients to live in a more sustainable manner in their homes, in their places of work, and indeed in their wider lifestyle choices.

The profession of an interior designer is not legally regulated; correspondingly, professionals in this domain are not obligated to follow any of the harmonisation of national or EU legislation. This suffers from major drawbacks in the implementation of promoted sustainable practices, as the professional bodies cannot impel designers to apply any expertise. As commented upon by [24], even though sustainable design has become one of the major concerns in the interior design industry, the frequency of making such sustainable adoptions in real practice largely remains inadequate. However, it is encouraging to know that interior design professionals' and professors even if they are not committed to any legislative obligation are willing to work towards a more sustainable environment.

Finally, all sustainable development programs should take into consideration the view of Arbuthnott [25] which is consistent with the findings presented that the aspects that influence behavioural change are also expected to be affected by education focused on attitudes and values.

\section{REFERENCES}

[1] European Council of Interior Architects (2007). European Charter of Interior Architecture Training 2007

[2] Ioannou Kazamia K., PhD (2019) ‘Sustainable Interior Design: A Model to Promote Sustainable Practices, University of Nicosia, Nicosia, Cyprus

[3] Coleman, C. (2000). Design ecology: Assessing the future of green design. Chicago: International Interior Design Association. Chicago, Illinois.

[4] Pollack, S. J. \& Pillote, L. (2006). Preliminary Teaching Manual for Sustainable Design Education, Interior Designers Educators Council.

[5] UNESCO. Education for Sustainable Development in Action Learning \& Training Tools $\mathrm{N}^{\circ} 1$ 2006. UNESCO Education Sector, October 2006

[6] Cyprus Pedagogical Institute. A Guide to Education in Cyprus. Nicosia: Ministry of Education and Culture, Cyprus Pedagogical Institute, 2011.

[7] UNECE Steering Committee on Education for Sustainable Development (2005). 13-14 December 2005. Netherlands: University Press. pp 9-20.

[8] European Environment Agency, Code of Federal Regulations, 2012

[9] Bakas, I. (2013) Municipal waste management in Cyprus. Copenhagen Resource Institute

[10] Republic of Cyprus, Ministry of Interior, 2015

[11] Lapithis, P. (2007). Cyprus. In: P. Jones, P. Pinho, J. Patterson, C. Tweed, eds. 2007. European carbon atlas. Cardiff: Welsh School of Architecture. pp. 20-30.

[12] Electricity Authority of Cyprus. (2014). To be a leader in sustainability. [online] Retrieved from http://www.eac.com.cy/EN/eac/sustainability/Pages/sustainableacchievments.aspx [Accessed 4 April 2014].

[13] CYMEPA. (n.d.). Cyprus Marine Environment Protection Association. [online] Retrieved from http://www.cymepa.org.cy/el/page/home. [Accessed 14 September 2014].

[14] Environmental Studies Centre. (n.d.). History. [online] Retrieved from http://www.esc.com.cy/11history/history.htm [Accessed4 April 2014].

[15] Republic of Cyprus, Ministry of Education and Culture, 2011

[16] Hadjivasiliou Christos, Sustainable Principles for the Developing Educational Environments in Cyprus. Thesis, Department of Architecture, Nicosia, UNIC, Cyprus, May 2012

[17] Pile, J. (1988). Interior design. New York: Harry N. Abrams. Pile, J. (1995). Interior design, 2nd ed. New York: Prentice Hall. 
[18] Null R. (2014). Universal Design Principles and Models. Washington DC: CRC Press

[19] American Society of Interior Designers (ASID). (2000). Energy Policy Act. [Online] Available at: https://www.asid.org/content/asid-position-sustainabledesign\#.VqTcEfl97IU [Accessed: on 24 January 2016].

[20] Stelmack, A. (2014). Sustainable Residential Interiors. Wiley. American Society of Interior Designers.

[21] Krathwohl, D., Bloom, B., \& Masia, B. (1964). Taxonomy of educational objectives: The classification of educational goals. New York: Longman.

[22] McNiff, J. (1988). Action Research: Principles and Practice. London: McMillan.

[23] Bloom, B., Englehart, M. Furst, E., Hill, W., \& Krathwohl, D. (1956). Taxonomy of educational objectives: The classification of educational goals. Handbook I: Cognitive domain. New York and Toronto: Longmans, Green.

[24] Lee, E., Allen, A., and Kim, B. (2013). Interior design practitioner motivations for specifying sustainable materials: applying the theory of planned behaviour to residential design. Journal of Interior Design, 38(4), pp.1-16.

[25] Arbuthnott, K. (2008). 'Education for sustainable development beyond attitude change'. International Journal of Sustainability in Higher Education, 10(2), pp. 152-163. 